\title{
ENRAIZAMENTO DE ESTACAS HERBÁCEAS DE QUATRO CLONES DE UMEZEIRO (Prunus mume Sieb. et Zucc.) DURANTE O INVERNO AMENO, EM JABOTICABAL-SP ${ }^{1}$
}

\author{
NEWTON ALEX MAYER² \& FERNANDO MENDES PEREIRA³
}

\begin{abstract}
RESUMO -Estudos realizados no Brasil com o umezeiro (Prunus mume Sieb. et Zucc.) relatam promissoras perspectivas de utilização desta espécie como porta-enxerto para pessegueiro e nectarineira, em função de sua rusticidade, adaptação ao inverno brando, compatibilidade com Prunus persica, redução do vigor das plantas e melhoria da qualidade dos frutos. Entretanto, em função da propagação por sementes, tem sido observadas diferenças de vigor entre as plantas, resultando em pomares muito heterogêneos. Assim, o presente estudo teve por objetivo estudar o enraizamento de estacas herbáceas de quatro clones de umezeiro (Clones 02, 05, 10 e 15) durante o inverno ameno, em Jaboticabal-SP. O experimento foi conduzido entre os meses de junho e agosto, sendo avaliado aos 70 dias após a estaquia. Pelos resultados obtidos, foi possível concluir que é viável a propagação dos clones estudados por enraizamento de estacas herbáceas durante o inverno. Foram observadas diferenças entre os clones quanto à porcentagem de enraizamento, porcentagem de estacas com calo, número e comprimento das raízes. No conjunto das variáveis analisadas, os melhores resultados foram obtidos com os Clones 10 e 15 .
\end{abstract}

Termos de indexação: propagação vegetativa, porta-enxerto, frutas de caroço.

\section{ROOTING OF HERBACEOUS CUTTINGS OF FOUR MUME CLONES (Prunus mume Sieb. et Zucc.) DURING SOFT WINTER, IN JABOTICABAL, SÃO PAULO STATE, BRAZIL}

\begin{abstract}
Studies developed in Brazil with the mume (Prunus mume Sieb. et Zucc.) have shown promising perspectives of using this species as rootstock for peach and nectarine trees, in function of its rusticity, adaptation to soft winter, compatibility with Prunus persica, plant vigor reduction and improvement of the fruit quality. However, due to seed propagation, vigor differences have been observed among plants, resulting in very heterogeneous orchards. Thus, the present study had the objective of studying the rooting of herbaceous cuttings of four mume clones (Clones 02 , 05,10 and 15) in intermittent mist during the soft winter, in Jaboticabal, São Paulo State, Brazil. The experiment was carried out between June and August, being evaluated 70 days after the cutting. From the obtained results, it was possible to conclude that the propagation of the clones studied is viable through the rooting herbaceous cuttings during the winter. Differences were observed among the clones with relationship to rooting percentage, callus percentage, root number and length. Grouping all the analyzed variables the best results were obtained with the Clones 10 and 15 . Index terms: vegetative propagation, rootstock, stone fruits.
\end{abstract}

\section{INTRODUÇÃO}

No Brasil, a cultura do pessegueiro ocupa área de 22.039 hectares, destacando-se o Rio Grande do Sul como o principal produtor, com 14.344ha, seguido pelos Estados de Santa Catarina (3.056ha), São Paulo (2.133ha), Paraná (1.796ha) e Minas Gerais (696ha) (Agrianual, 2003).

Embora o Rio Grande do Sul seja o maior produtor brasileiro, a produtividade média neste Estado é muito baixa, em torno de 6 a 7 toneladas.ha ${ }^{-1}$ (Raseira \& Nakasu, 1998). Um dos fatores que poderia contribuir para o aumento da produtividade na cultura seria o adensamento dos pomares, tendência observada para a maioria das culturas perenes no Estado de São Paulo (Caser et al., 2000). Em frutíferas de caroço, segundo estes autores, houve aumentos na densidade de plantio em $57,1 \%$ para o pessegueiro destinado ao mercado in natura, $35,7 \%$ no pessegueiro com fins industriais, $69,0 \%$ nas nectarineiras e $32,1 \%$ na ameixeira, em relação aos indicadores anteriormente adotados, o que pode influenciar diretamente o rendimento das operações de cultivo, os níveis de produtividade e o custo de produção da cultura. Para viabilizar tecnicamente o adensamento dos pomares, uma das alternativas seria a utilização de porta-enxertos menos vigorosos ou ananizantes.

O umezeiro ou damasqueiro-japonês (Prunus mume Sieb. et Zucc.) desperta grande interesse pela pesquisa brasileira em função das seguintes características: rusticidade, sanidade e adaptação ao inverno brando (Campo Dall'Orto et al., 1995/1998). Segundo Sherman \& Lyrene (1983), o umezeiro apresenta altos níveis de resistência a nematóides de galhas, o que foi comprovado posteriormente para Meloidogyne incognita e para M.javanica (Rossi et al., 2002; Mayer et al., 2003), características estas desejáveis em um bom porta-enxerto e que devem ser exploradas na fruticultura.

Estudos envolvendo o umezeiro como porta-enxerto para pessegueiro e nectarineira revelaram a compatibilidade entre estas espécies, com as vantagens de redução do vigor das copas em até $50 \%$, produtividade compatível com esse menor porte e frutos com maior massa e teor de sólidos solúveis, realçando a pigmentação vermelha da película, quando comparados aos frutos produzidos pelos mesmos cultivares enxertados sobre o cv. Okinawa (Campo Dall'Orto et al., 1992 e 1994; Nakamura et al., 1999). Entretanto, nestes estudos, observou-se variabilidade do porte entre plantas de um mesmo cultivar-copa, em decorrência da propagação por sementes do umezeiro, o que sugere a necessidade de propagação vegetativa, objetivando a uniformidade do pomar e a manutenção dos caracteres da planta-matriz.

Dentre os métodos de propagação vegetativa, a estaquia herbácea em câmara de nebulização intermitente durante o outono tem apresentado resultados satisfatórios para o umezeiro (Nachtigal et al., 1999; Mayer et al., 2002). Melhores resultados foram observados na primavera (Mayer et al., 2001), com porcentuais de enraizamento variando de 78,13 a 93,75\%, o que viabiliza a propagação em nível comercial da espécie por este método. Estacas herbáceas de umezeiro com $12 \mathrm{~cm}$ apresentam resultados satisfatórios, permitindo maior rendimento de estacas por planta-matriz em relação às estacas com 25 cm (Mayer et al., 2002). A realização de dois cortes superficiais opostos na base das estacas herbáceas de umezeiro é uma prática desnecessária por não ter influenciado a porcentagem de enraizamento, além de que estacas sem lesão apresentaram satisfatória qualidade de raízes (Mayer $\&$ Pereira, 2002). Estes estudos revelaram que, em função do inverno ameno na região noroeste do Estado de São Paulo e das podas drásticas

\footnotetext{
(Trabalho 071/2003). Recebido: 30/05/2003. Aceito para publicação: 24/10/2003. Parte da dissertação apresentada pelo primeiro autor, para obtenção do título de Mestre em Agronomia no Programa de Produção Vegetal pela Faculdade de Ciências Agrárias e Veterinárias (FCAV/UNESP) - Campus de Jaboticabal-SP. Apoio Financeiro: FCAV/UNESP - Campus de Jaboticabal e CAPES.

${ }^{2}$ Eng. Agr., M.Sc., Doutorando em Agronomia, Departamento de Produção Vegetal, FCAV/UNESP- Via de Acesso Prof. Paulo Donato Castellane Km05 s/n, CEP 14884-900, Jaboticabal-SP. e-mail: namayer@fcav.unesp.br.

${ }^{3}$ Eng. Agr., Dr., Professor Titular do Departamento de Produção Vegetal da FCAV/UNESP, Campus de Jaboticabal-SP. e-mail: fmendes@fcav.unesp.br
} 
realizadas nas plantas matrizes, é possível a obtenção de ramos herbáceos de umezeiro para a estaquia em qualquer época do ano.

Desta forma, o objetivo do presente trabalho foi estudar o enraizamento de estacas herbáceas de quatro clones de umezeiro sob condições de inverno ameno, em Jaboticabal-SP.

\section{MATERIAIS E MÉTODOS}

Plantas matrizes de umezeiro (Prunus mume Sieb. et Zucc.) dos Clones $02,05,10$ e 15, selecionadas a partir de material em cultivo na Estação Experimental de Jundiaí-IAC, foram mantidas em vasos plásticos de 20 litros sob ripado com $50 \%$ de sombreamento, pertencente ao Departamento de Produção Vegetal da FCAV/UNESP, Campus de Jaboticabal-SP. O município localiza-se a $21^{\circ} 15^{\prime} 22^{\prime \prime}$ de latitude Sul e $48^{\circ}$ $18^{\prime} 58^{\prime \prime}$ de longitude Oeste, com altitude média de $595 \mathrm{~m}$, acima do nível do mar. Segundo a classificação de Köppen, o clima da região é do tipo Cwa, ou seja, subtropical úmido com estiagem durante o período de inverno.

Os ramos foram coletados de plantas matrizes com um ano de idade no começo de junho (90 dias após a poda de renovação). As estacas foram preparadas com $12 \mathrm{~cm}$ de comprimento, permanecendo de 3 a 5 folhas por estaca. As folhas do terço inferior foram retiradas para aplicação do regulador de crescimento e enterrio no substrato. Todas as estacas foram tratadas com IBA a 2.000 mg. $\mathrm{L}^{-1}$ (Mayer et al., 2001) e como substrato utilizou-se a vermiculita de grânulos médios. Para a contenção da vermiculita foram utilizadas caixas brancas de plástico perfuradas com as seguintes dimensões: $37,5 \mathrm{~cm} \times 27 \mathrm{~cm} \times 9,5 \mathrm{~cm}$ (comprimento $\mathrm{x}$ largura $\mathrm{x}$ altura).

O experimento foi conduzido em câmara de nebulização intermitente acionada por um temporizador ("timer"), o qual controlava a abertura e fechamento de uma válvula solenóide. Os períodos de nebulização e desligamento do sistema foram de 5 e 40 segundos, respectivamente, os quais foram determinados por observações visuais, de modo a manter uma fina camada de água sobre a superfície das folhas, sem causar escorrimentos. Os aspersores foram dispostos em linha, com distância de $1,5 \mathrm{~m}$ entre si e $2,0 \mathrm{~m}$ entre linhas, sendo que os bicos nebulizadores encontravam-se a $0,70 \mathrm{~m}$ do nível do solo.

Adotou-se o delineamento inteiramente casualizado com quatro repetições, sendo cada parcela constituída por 20 estacas. Os tratamentos foram constituídos dos quatro clones testados (Clone 02, Clone 05, Clone 10 e Clone 15). Aos 70 dias após a estaquia, as estacas foram retiradas das caixas para avaliações das seguintes variáveis: porcentagem de estacas enraizadas, porcentagem de estacas com calo, porcentagem de estacas mortas, porcentagem de estacas vivas brotadas, número de raízes por estaca e comprimento médio das cinco maiores raízes. Os resultados obtidos foram submetidos à análise de variância pelo teste $\mathrm{F}$ e as médias foram comparadas pelo teste de Tukey ao nível de $5 \%$ de probabilidade. As variáveis expressas em porcentagem foram transformadas para arco seno $\sqrt{\frac{P}{100}}$, onde $P$ significa o valor observado, sendo que as demais não foram transformadas.

\section{RESULTADOS E DISCUSSÃO}

As respostas dos diferentes clones de umezeiro nas variáveis porcentagens de estacas enraizadas, estacas com calo, estacas mortas e estacas vivas brotadas são apresentadas na Tabela 1. Pelo teste F observou-se uma diferença altamente significativa entre os clones quanto à porcentagem de estacas enraizadas. $\mathrm{O}$ maior porcentual de enraizamento foi observado no Clone $15(75,00 \%)$, mostrando-se bastante promissor ao enraizamento adventício. Os Clones 10 e 02 apresentaram, respetivamente, $58,75 \%$ e $42,80 \%$ de enraizamento e o Clone 05 a menor média, com 30,0\%. Estes resultados discordam dos obtidos por Nachtigal et al. (1999), que verificaram não haver diferenças estatísticas entre os mesmos clones do presente estudo, durante o outono, cujos valores obtidos encontraram-se entre 14,01 e $36,8 \%$ de estacas enraizadas. Segundo Mayer et al. (2001), a porcentagem de enraizamento do Clone 15 foi superior ao observado no Clone 02 durante a primavera, sendo que os Clones 05 e 10 comportaram-se como intermediários.

TABELA 1 - Porcentagens de estacas enraizadas, com calo, mortas e brotadas de quatro clones de umezeiro, tratadas com 2.000mg. $\mathrm{L}^{-1}$ de IBA e mantidas em câmara de nebulização intermitente durante o inverno ameno. FCAV/UNESP, Campus de Jaboticabal-SP.

\begin{tabular}{ccccc}
\hline Clones & $\begin{array}{c}\text { Estacas } \\
\text { enraizadas }\end{array}$ & $\begin{array}{c}\text { Estacas } \\
\text { com calo }\end{array}$ & $\begin{array}{c}\text { Estacas } \\
\text { mortas }\end{array}$ & $\begin{array}{c}\text { Estacas } \\
\text { brotadas }\end{array}$ \\
\cline { 2 - 5 } & \multicolumn{5}{c}{$\%$} \\
\hline Clone 02 & $42,80 \mathrm{c}$ & $19,41 \mathrm{ab}$ & $31,32 \mathrm{a}$ & $21,25 \mathrm{a}$ \\
Clone 05 & $30,00 \mathrm{~d}$ & $32,5 \mathrm{a}$ & $35,00 \mathrm{a}$ & $36,25 \mathrm{a}$ \\
Clone 10 & $58,75 \mathrm{~b}$ & $7,5 \mathrm{bc}$ & $31,25 \mathrm{a}$ & $19,63 \mathrm{a}$ \\
Clone 15 & $75,00 \mathrm{a}$ & $5,0 \mathrm{c}$ & $18,75 \mathrm{a}$ & $36,25 \mathrm{a}$ \\
\hline $\mathrm{F}$ & $52,96^{* *}$ & $10,79^{* *}$ & $2,16^{\mathrm{NS}}$ & $2,09^{\mathrm{NS}}$ \\
\hline $\mathrm{CV}(\%)$ & 6,97 & 29,00 & 20,48 & 25,79 \\
\hline
\end{tabular}

Médias seguidas por letras distintas, na mesma coluna, diferem entre si pelo teste de Tukey. ${ }^{* *}$ significativo ao nível de $1 \%$ de probabilidade; Ns não significativo.

Para Reuveni \& Raviv (1981), a influência do material genético na propagação vegetativa pode ser devida à maior capacidade de retenção foliar dos materiais mais promissores. O número de folhas retidas também se correlacionaria positivamente com a velocidade de enraizamento. Embora não tenham sido realizados estudos de correlação entre retenção foliar e enraizamento no presente estudo, visualmente foi observado que praticamente $100 \%$ das estacas enraizadas apresentavam, pelo menos, uma folha oriunda do ramo que deu origem à estaca. A ausência de folhas resultou, em praticamente todos os casos, em estacas com calo ou mortas. Segundo Hartmann \& Loreti (1965), os dias curtos do outono e inverno, a baixa intensidade luminosa e as baixas temperaturas do ambiente influenciam no processo fotossintético, sendo estas as causas dos piores resultados observados nestas estações em relação à primavera e verão. De acordo com Muñoz \& Valenzuela (1978), a porcentagem de enraizamento diminui à medida que se avança na estação de crescimento. Essa diminuição se deve às variações do conteúdo de cofatores e/ou à formação e acumulação de inibidores do enraizamento.

Com relação à porcentagem de estacas com calo também foi observada diferença estatística altamente significativa entre os clones, segundo o teste $\mathrm{F}$. As maiores porcentagens foram observadas nos Clones 05 (32,5\%), que foi semelhante ao Clone $02(19,41 \%)$, mas superior aos Clones $10(7,5 \%)$ e $15(5,0 \%)$. Nesta variável, o Clone 02 foi semelhante aos Clones 05 e 10, mas superior ao Clone 15. Segundo Erez (1984), o processo de formação de calo estaria ligado às baixas temperaturas. Em estacas lenhosas de pessegueiro, exposições por 60 dias, a temperaturas iguais ou inferiores a $9^{\circ} \mathrm{C}$, apresentaram formação de calo com ausência de raízes. Portanto, as menores temperaturas observadas durante a condução do presente estudo pode ter sido o fator responsável pelos maiores porcentuais de estacas com calo em relação ao relatado por Mayer et al. (2001)

Embora não tenha sido detectada diferença estatística entre os clones quanto à porcentagem de estacas mortas, os porcentuais variaram de $18,75 \%$ (Clone 15 ) a 35,0\% (Clone 05 ) e considerados como valores perfeitamente aceitáveis para a espécie. Nachtigal (1999) cita o baixo índice de enraizamento, a permanência prolongada na câmara de nebulização e o excesso de umidade do ambiente e do substrato como fatores que podem elevar a mortalidade das estacas.

Também não foi detectada diferença estatística significativa na porcentagem de estacas brotadas em função dos clones testados, cujos valores situaram-se entre 19,63 e 36,25\%. Esta semelhança estatística concorda com Mayer et al. (2001), entretanto, os valores observados por estes autores foram todos superiores a $80 \%$ para os mesmos clones, em função da época do ano (primavera). A brotação da estaca durante o período de enraizamento é comum em estacas herbáceas de umezeiro e pode auxiliar na sobrevivência das estacas enraizadas após a retirada da câmara de nebulização, em função de não interromper o processo 
fotossintético.

Os valores referentes ao número de raízes por estaca e comprimento de raízes são apresentados na Tabela 2. Observou-se diferença altamente significativa entre os clones, no número de raízes por estaca. O Clone 10, com média semelhante ao Clone 15, mas superior aos Clones 02 e 05. O Clone 15, com média semelhante ao Clone 10 e ao Clone 02, mas superior ao Clone 05. Os Clones 02 e 05 apresentaram médias semelhantes para número de raízes por estaca. Para Nachtigal et al. (1999) e Mayer et al. (2001) não houveram diferenças entre os clones para o número de raízes por estaca. Entretanto, segundo estes autores, a imersão da base das estacas em solução de IBA a $2.000 \mathrm{mg} . \mathrm{L}^{-1}$ por cinco segundos teria influência nesta variável, aumentando o número de raízes.

TABELA 2 - Número de raízes por estaca e comprimento médio de raízes em estacas herbáceas, tratadas com 2.000mg.L $\mathrm{L}^{-1} \mathrm{de}$ IBA, de quatro clones de umezeiro mantidas em câmara de nebulização intermitente durante o inverno ameno. FCAV/UNESP, Campus de Jaboticabal-SP.

\begin{tabular}{ccc}
\hline Clones & $\begin{array}{c}\text { Número de raízes } \\
\text { por estaca }\end{array}$ & $\begin{array}{c}\text { Comprimento médio } \\
\text { de raízes (cm) }\end{array}$ \\
\hline Clone 02 & $4,52 \mathrm{bc}$ & $2,29 \mathrm{~b}$ \\
Clone 05 & $3,66 \mathrm{c}$ & $2,53 \mathrm{~b}$ \\
Clone 10 & $6,75 \mathrm{a}$ & $3,81 \mathrm{a}$ \\
Clone 15 & $5,93 \mathrm{ab}$ & $2,58 \mathrm{~b}$ \\
\hline $\mathrm{F}$ & $9,77^{* *}$ & $5,63 *$ \\
\hline CV $(\%)$ & 17,04 & 20,64 \\
\hline
\end{tabular}

Médias seguidas por letras distintas, na mesma coluna, diferem entre si pelo teste de Tukey. * significativo ao nível de $5 \%$ de probabilidade; ** significativo ao nível de $1 \%$ de probabilidade.

Para a variável comprimento médio das cinco maiores raízes foram observadas diferenças estatísticas entre os clones, sendo que o Clone 10 foi superior aos Clones 15, 05 e 02. Estes resultados também não concordam com Nachtigal et al. (1999) e Mayer et al. (2001), os quais relatam a ausência de diferenças significativas entre os mesmos clones para essa característica. Um aspecto importante em estudos de enraizamento refere-se a análise conjunta das variáveis número e comprimento de raízes, pois não é de interesse prático uma estaca que produza uma única raiz longa ou várias raízes de pequeno comprimento. Portanto, deve-se buscar uma determinada condição ou tratamento que resulte no equilíbrio destas variáveis, ou seja, uma estaca que produza várias raízes com um bom crescimento, em um curto espaço de tempo, $\mathrm{o}$ que aumenta as chances de sobrevivência após a retirada da câmara de nebulização.

\section{CONCLUSÕES}

Nas condições experimentais em que o trabalho foi conduzido pode-se concluir que:

1) É viável a propagação dos Clones $02,05,10$ e 15 de umezeiro por estacas herbáceas, sob condições de inverno ameno, com porcentuais de enraizamento superiores a $30 \%$;

2) Existem diferenças entre os clones quanto à porcentagem de estacas enraizadas, porcentagem de estacas com calo, número e comprimento de raízes.

3) A análise conjunta das variáveis estudadas apontam os Clones 10 e 15 como os mais efetivos para a propagação por estacas herbáceas no inverno.

\section{REFERÊNCIAS BIBLIOGRÁFICAS}

AGRIANUAL 2003: anuário da Agricultura Brasileira. São Paulo: FNP Consultoria \& Comércio, 2003. p.446-450.

CAMPO DALL'ORTO, F.A.; OJIMA, M.; BARBOSA, W.; MARTINS, F.P. O nanismo do pessegueiro induzido pela enxertia no damasqueiro-japonês. Pesquisa Agropecuária Brasileira, Brasília, v.27, n.3, p.517-521, 1992.
CAMPO DALL'ORTO, F.A.; BARBOSA, W.; OJIMA, M.; MARTINS, F.P; FOBÉ, L.A. Comportamento de pessegueiros IAC enxertados no damasqueiro japonês e no pessegueiro 'Okinawa'. In: CONGRESSO BRASILEIRO DE FRUTICULTURA, 13., 1994, Salvador. Anais... Salvador: SBF, 1994. v.3, p.879-880.

CAMPO DALL'ORTO, F.A.; OJIMA, M.; BARBOSA, W.; MARTINS, F.P. Damasco-japonês (umê) em São Paulo: opção para o século 21. O Agronômico, Campinas, v.47/50, p.18-20, 1995/1998. (Boletim Técnico Informativo).

CASER, D.V.; CAMARGO, A.M.M.P. de.;AMARO, A.A. Densidades de plantio em culturas perenes na agricultura paulista. Informações Econômicas, São Paulo, v.30, n.7, p.45-53, 2000.

EREZ, A. Improving the rooting of peach hardwood cuttings under field conditions. HortScience, Alexandria, v.19, n.2, 245-247, 1984.

HARTMANN, H.T.; LORETI, F. Seasonal variation in rooting leafy olive cuttings under mist. Proceedings of the American Society Horticultural Science, Geneva, v.87, p.194-198, 1965.

MAYER, N.A.; PEREIRA, F.M.; NACHTIGAL, J.C. Propagação do umezeiro (Prunus mume Sieb \& Zucc.) por estaquia herbácea. Revista Brasileira de Fruticultura, Jaboticabal, v.23, n.3, p.673$676,2001$.

MAYER, N.A.; PEREIRA, F.M. Incision effect in the cuttings herbaceous base in the rooting of four japanese apricot clones (Prunus mume Sieb. et Zucc.) in intermittent mist. In: INTERNATIONAL SYMPOSIUMON ROOTSTOCKS FOR DECIDUOUS FRUIT TREE SPECIES, 1., 2002, Zaragoza. Abstracts...Zaragoza: ISHS, CSIC and CIHEAM, 2002. p.13.

MAYER, N.A.; PEREIRA, F.M.; NACHTIGAL, J.C. Efeito do comprimento de estacas herbáceas de dois clones de umezeiro (Prunus mume Sieb \& Zucc.) no enraizamento adventício. Revista Brasileira de Fruticultura, Jaboticabal, v.24, n.02, p.500-504, 2002.

MAYER, N.A.; PEREIRA, F.M.; SANT OS, J.M. dos. Reação de clones de umezeiro (Prunus mume Sieb. et Zucc.) e cultivares de pessegueiro a Meloidogyne javanica (Treub, 1885) Chitwood, 1949. Revista Brasileira de Fruticultura, Jaboticabal, v.25, n.01, p.181183, 2003. MUÑOZ, I.H.; VALENZUELA, J.B. Enraizamiento de estacas herbáceas de tres cultivares de vid: efecto de la ubicación en el sarmiento y época de recolección. Agricultura Tecnica, Santiago, v.38, n.1, p.14-17, 1978.

NACHTIGAL, J.C. Obtenção de porta-enxertos 'Okinawa' e de mudas de pessegueiro ( Prunus persica $(\mathbf{L}$.) Batsch) utilizando métodos de propagação vegetativa. 1999. 165f. Tese (Doutorado em Agronomia) - Faculdade de Ciências Agrárias e Veterinárias, Universidade Estadual Paulista, Jaboticabal, 1999.

NACHTIGAL, J.C.; PEREIRA, F.M.; CAMPO DALL'ORTO, F.A.; OJIMA, M.; MARTINS, F.P. Propagação vegetativa do umezeiro (Prunus mume) por meio de estacas herbáceas. Revista Brasileira de Fruticultura, Jaboticabal, v.21, n.2, p.226-228, 1999.

NAKAMURA, C.H.; SCARPARE FILHO, J.A.; KLUGE, R.A. Avaliação preliminar do umezeiro como porta-enxerto para pessegueiro e nectarineira. Revista Brasileira de Fruticultura, Jaboticabal, v.21, n.2, p.116-118, 1999.

RASEIRA, M. do C.B.; NAKASU, B.H. Situação e perspectivas do cultivo de fruteiras de clima temperado no Rio Grande do Sul Frutas de caroço. In: REUNIÃO TÉCNICA DE FRUTICULTURA, 5., 1998, Veranópolis. Anais... Porto Alegre: Fepagro, 1998. p.21-22.

REUVENI, O.; RAVIV, M. Importance of leaf retention to rooting of avocado cuttings. Journal of the American Society for Hoticultural Science, Alexandria, v.106, n.2, p.127-130, 1981.

ROSSI, C.E.; FERRAZ, L.C.C.B.; MONTALDI, P.T. Resistência de frutíferas de clima subtropical e temperado a Meloidogyne incognita raça 2 e M.javanica. Arquivos do Instituto Biológico, São Paulo, v.69, n.2, p.43-49, 2002.

SHERMAN, W.B.; LYRENE, P.M. Improvement of peach rootstock resistant to root-knot nematodes. Proceedings of the Florida State Horticultural Society, Winter Haven, v.96, p.207-208, 1983. 